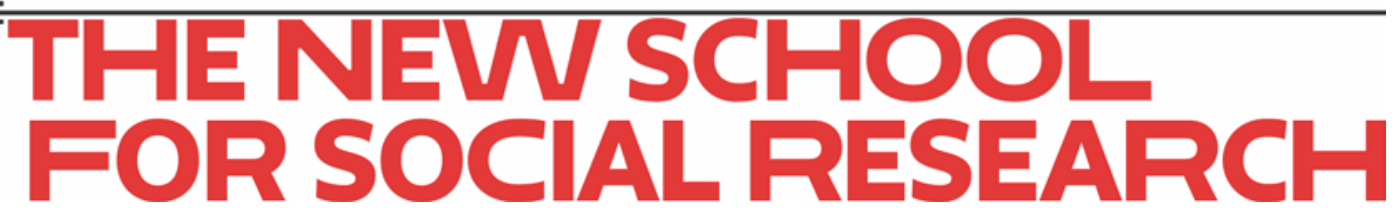

Christian Schoder

\title{
A Keynesian Dynamic Stochastic Disequilibrium model for business cycle analysis
}

January 2017

Working Paper 01/2017

Department of Economics

The New School for Social Research 


\title{
A Keynesian Dynamic Stochastic Disequilibrium model for business cycle analysis.*
}

\author{
Christian Schoder ${ }^{\dagger}$
}

January 9, 2017

\begin{abstract}
A Dynamic Stochastic Disequilibrium (DSDE) model is proposed for business cycle analysis. Unemployment arises from job rationing due to insufficient aggregate spending. The nominal wage is taken as a policy variable subject to a collective Nash bargaining process between workers and firms with the state of the labor market affecting the relative bargaining power. A precautionary saving motive arising from an uninsurable risk of permanent income loss implies an equilibrium relation between consumption, income and wealth. The DSDE model differs from the corresponding Dynamic Stochastic General Equilibrium (DSGE) model with labor market clearing in important respects: $(i)$ Output is determined from the demand side and not from the supply side; (ii) The steady-state interest rate cannot be interpreted as a natural rate; (iii) It has to be smaller than the rate of economic growth in order for a steady state to exist; (iv) Determinacy of the solution requires the monetary policy response to inflation to be high (low) at low (high) steady-state interest rates; $(v)$ Fighting inflation is stabilizing in the active monetary policy regime but destabilizing in the passive monetary policy regime; (vi) Macroeconomic responses to monetary policy and productivity shocks are similar to those of the DSGE model but give more weight to quantity adjustment and predict the real wage to increase with productivity.
\end{abstract}

Keywords: Dynamic stochastic disequilibrium, labor market disequilibrium, labor rationing, collective wage bargaining, monetary policy

JEL Classification: B41, E12, J52

\footnotetext{
${ }^{*}$ For valuable comments and suggestions, I would like to thank Katrin Rabitsch, Peter Skott, and Thomas Palley. Earlier drafts of the paper have been presented at workshops of the Vienna University of Economics and Business in 2014, and of the University of Technology in Vienna in 2014. The paper has greatly benefited from comments by participants. Finally financial support by the Hans-Böckler Foundation is gratefully acknowledged. The usual caveats apply.

${ }^{\dagger}$ The New School for Social Research, 6 East 16th Street, New York, NY 10003. Email: schoderc@newschool.edu
} 


\section{Introduction}

Since the world financial crisis unemployment has soared in the Euro Area from a low of $7.5 \%$ in 2008 to a high of $11.6 \%$ in 2014 and stayed above 10\% at least until 2016 (OECD Economic Outlook 2016). In particular, Greece, Spain, Italy and Portugal as well as France exhibit persistent labor market problems with unemployment hikes between $10 \%$ and $27 \%$. At the same time, ambitious labor market reforms have been implemented in the southern European countries reducing the level of security for both the employed and unemployed population (cf. Moreira et al. 2015 and Karamessini 2015).

In conventional search and matching theories of unemployment developed by Mortensen and Pissarides (1994), extended by Shimer (2005) to include wage rigidities and introduced to Dynamic Stochastic General Equilibrium (DSGE) models by Hall (2005), Gertler et al. (2008) and Gertler and Trigari (2009), unemployment originates solely from labor market frictions, both over the cycle and in the steady state. Hence, eliminating costs related to the hiring and firing of employees would eliminate unemployment. The observation of persistently high unemployment rates despite considerable labor market reforms challenges the hypothesis that current unemployment is purely frictional.

Rationing theories of unemployment have attempted to solve this empirical puzzle. The crucial assumption is that the wage does not adjust sufficiently to clear the labor market over the cycle or even in the steady state in the absence of matching frictions. Michaillat (2012) assumes the real wage to increase less than one-by-one with productivity and with a decreasing rate and finds that unemployment arises mainly due to job rationing rather than frictions in recessions. ${ }^{1}$ Partial labor market equilibria arise which exhibit disequilibrium unemployment going beyond purely frictional equilibrium unemployment.

Introducing rationing unemployment has vast repercussions on the overall structure of the economic model as we move from the realm of general equilibrium to the realm of disequilibrium theory. ${ }^{2}$ Output is no more determined through the factor markets combined with a production functions (supply side) but by the spending decisions of the economic agents which may imply disequilibrium factor employment at a given factor price.

The present paper proposes a new framework referred to as Dynamic Stochastic Disequilibrium model which combines disequilibrium theory with inter-temporal optimization and rational expectations. The model has two core features: First, I take the rate of wage inflation as a policy variable subject to a collective bargaining process between firms' and workers' representatives rather than as an accommodating variable that gives rise to privately efficient wage contracts. Hence, the labor market does not clear in equilibrium. Keynesian unemployment prevails, labor is not employed optimally. With output being determined by the demand side, a conventional setup of the household's problem would make the steady-state level of consumption indeterminate. ${ }^{3}$ Second, I therefore introduce an uninsurable risk of permanent income loss to the household's problem which motivates

\footnotetext{
${ }^{1}$ This type of wage rule has been suggested by Blanchard and Gali (2010) and shown to be consistent with equilibrium under hiring frictions by Hall (2005).

${ }^{2}$ Disequilibrium theory has been popularized by Barro and Grossman (1971) which is the first micro-founded version of Keynes' (1936) framework and has generated a vast literature in the 1970s (Barro R 1976, Malinvaud 1977, Benassy 1993). Since the Great Recession a renewed interest in disequilibrium theory emerged (Mankiw and weinzierl 2011, Caballero and Farhi 2014, Korinek and Simsek 2014).

${ }^{3}$ The conventional household's problem determines consumption smoothing but not the level of consumption. The latter is implied by the resource constraint given the investment decision and government consumption (cf. Smets and Wouters 2003).
} 
the existence of precautionary savings and provides a mechanism by which consumption depends on income and wealth even in equilibrium. This amounts to a Keynesian type of consumption function (Carroll 1997, Carroll and Jeanne 2009, Carroll and Toche 2009). ${ }^{4}$

We discuss in detail the following model implications: First, output is determined from the demand side as known from the textbook IS-LM model. Even with fixed factor supply, a demand shock will affect output due to the presence of idle labor in equilibrium. Second, in contrast to DSGE models, the steady-state interest rate in the DSDE model does not have the interpretation of a natural rate. It is not determined by the household's discount rate but set by the central bank. Third, while dynamic efficiency in DSGE models requires the real interest rate to exceed the growth rate of the economy, the opposite has to hold in the DSDE model to ensure that the stock of wealth does no explode. Fourth, the DSDE model features two monetary policy regimes: At low steady-state interest rates, monetary policy needs to respond aggressively to inflation in order to ensure determinacy of the rational expectations solution. This is similar to the Taylor principle in the DSGE literature. Yet at high steady-state interest rates, a unique solution exists only if the central bank responds moderately to inflation. Fifth, in the passive monetary policy regime at high steady-state interest rates, monetary policy responding to inflation destabilizes output and reinforces inflation. Sixth, the adjustment of quantities relative to the adjustment of prices is more pronounced in the DSDE model than in the corresponding DSGE models. Finally, productivity and the real wage move together in the DSDE model.

Leaving the realm of general equilibrium theory may appear as a radical step. For the following reasons, it may still be a worthwhile exercise: First, given unemployment rates of up to $50 \%$ in the low-skilled segments of the labor market of some European countries, combined with considerable prevalence of binding minimum wages and collective wage agreements, disequilibrium unemployment may be an important aspect of European labor markets. The model can be seen as a first attempt to understand policy propagation mechanisms if labor resources are permanently under-utilized. ${ }^{5}$ Second, what is ok for the interest rate should also be fine for the wage. DSGE models typically take the price of capital, i.e. the interest rate, as an administered price determined by a policy rule. Only its long-run level relative to the inflation target of the monetary authority is restricted by the household's Euler equation. The bond market still clears at a given interest rate because any bond issued has to be held by someone. Equivalently, I perceive the wage as an administered price and abstract from market forces in the same way as DSGE models abstract from the term structure of the interest rate. The consequences of this additional but equivalent assumption are enormous. At a given wage, not any unit of labor supplied needs to be employed. Hence, a disequilibrium on the labor market may arise while this is not possible on the bond market. Third, Michailat's 2014 concern that leaving the general equilibrium framework may lead to ignoring the supply side can be addressed satisfyingly. In particular, the DSDE model features a labor market feedback on the wage formation through endogenous relative bargaining power. Hence, the supply side affects output through the demand side. Nevertheless, I will abstract from unemployment insurance, mismatch, labor force participation and labor taxes in order to keep the model tractable. The emphasis of the demand side is consistent with Farmer (2008) and Mian and Sufi (2014) who identify recent US business fluctuations to be mainly a demand side phenomenon. Finally, the

\footnotetext{
${ }^{4}$ While Michaillat and Saez (2014), fu Zou (1995, 1998), Bakshi and Chen (1996) include wealth in the utility function, we obtain it as a result from the risk of income loss.

${ }^{5} 62 \%$ of wage contracts in the Euro Area are governed by collective wage agreements. In July 2014, the Deutsche Bundesbank has recommended the wage bargainers to pursue higher wage agreements which supports the interpretation of the nominal wage as a policy variable.
} 
disputed contributions by Blanchard (2016) and Romer (2016) forcefully argue to explore models beyond the general equilibrium paradigm. The present paper is a first attempt to do so within a tractable framework.

The remainder of the paper proceeds as follows. Section 2 presents the DSDE model. Section 3 discusses model implications focusing on the nature of adjustment, the interpretation of the longrun rate of interest, the question of dynamic efficiency, and equilibrium stability and determinacy. Section 4 compares the macroeconomic responses to a monetary policy shock as predicted by different model variants including the DSGE models corresponding to the proposed DSDE model. Section 5 concludes the paper.

\section{The model}

I consider a closed economy populated by a number of active and inactive households, a representative final goods firm, a continuum of intermediate goods firms, a monetary and fiscal policy authority, and workers' and firms' representatives in the wage bargaining process.

I state all aggregated equations characterizing the DSDE model. Let $\Gamma$ denote the deterministic gross growth rate of the economy arising from labor embodied productivity growth. I use the following notation: $\tilde{X}_{t} \equiv X_{t} / \Gamma^{t}$ for any aggregated variable $X_{t}$.

\subsection{Households}

Individuals are born into generations of constant size. Each household is born into the labor force and supplies labor hours which the firm will employ to some extent. This type of household is referred to as active. In each period, the active household faces the risk of a permanent income loss, i.e. becoming inactive, which it cannot insure against. Once the household is inactive it cannot return to the active state. It faces the risk of death with a constant probability. While active, the rational household will accumulate precautionary savings as a buffer for the time when inactive.

Let $\Theta_{a, t}$ and $\Theta_{i, t}$ denote the period $t$ population sizes of active and inactive households, respectively. Every newborn generation of active households is of size one. The law of motion of the active population size then is

$$
\Theta_{a, t}-\Theta_{a, t-1}=1-U \Theta_{a, t-1}
$$

where $U$ is the per-period risk of becoming inactive. The law of motion of the inactive population size is

$$
\Theta_{i, t}-\Theta_{i, t-1}=U \Theta_{a, t-1}-D \Theta_{i, t-1}
$$

where $D$ is the per-period risk of dying. The steady-state size of each household type can be shown to be $\Theta_{a}=1 / U$ and $\Theta_{i}=1 / D$. Since every newborn cohort has size one and the active and inactive population sizes are stable, the flows from active to inactive and inactive to dead are of size one as well.

Inactive households. Let us consider, in period $t$, a representative inactive household $i$ which became inactive in period $t-s$ with $s \in\{0,1, \ldots, \infty\}$. Inactive households do not obtain labor or profit income and face a per-period probability, $D$, of death independent of their age. While we will 
make an assumption that ensures wealth to be homogenous across active households, this is not the case for inactive households. Households entering the inactive state at the same time $t-s$ will have the same wealth, but households entering this state at different times $t-s$ will have different stocks of wealth. To facilitate aggregation over inactive households, I adapt the perpetual youth framework proposed by Blanchard (1985). Inactive households have access to an insurance market to hedge against the risk of accidental bequests: The household sells, to an insurance company, the right to inherit its wealth $R_{t} P_{t} b_{i, t-s, t}$ at the beginning of period $t$ in case of dying between $t$ and $t+1 . R_{t}$ is the nominal interest rate, $P_{t}$ the price level and $b_{i, t-s, t}$ the end-of-period $t$ real wealth held by the household which became inactive in $t-s$. In turn, it receives the flow value of inheriting this wealth, i.e., $D R_{t} P_{t} b_{i, t-s, t}$ in $t$. Its problem is to choose optimal paths for consumption $c_{i, t-s, t}$ and wealth $b_{i, t-s, t}$ conditional on being alive and subject to the per-period budget constraint $P_{t} c_{i, t-s, t}+P_{t} b_{i, t-s, t}=R_{t-1} P_{t-1} b_{i, t-s, t-1}+D R_{t-1} P_{t-1} b_{i, t-s, t-1}$. Assuming log-utility, the inactive household's problem can be represented by the following dynamic program:

$$
\begin{aligned}
V_{i}\left(b_{i, t-s, t-1}\right)= & \max _{c_{i, t-s, t}}\left\{\ln c_{i, t-s, t}+\beta(1-D) \mathrm{E}_{t} V_{i}\left(b_{i, t-s, t}\right)\right\} \\
& \quad \text { s.t. } \quad c_{i, t-s, t}+b_{i, t-s, t}=\frac{R_{t-1}(1+D)}{\Pi_{p, t}} b_{i, t-s, t-1}
\end{aligned}
$$

where $\beta$ is the discount factor and $\Pi_{p, t}$ is the gross rate of price inflation from $t-1$ to $t$. $V_{i}\left(b_{i, t-s, t-1}\right)$ is the value function in $t$ and $b_{i, t-s, t-1}$ the state variable. Before solving this problem let us substitute out $b_{i, t-s, t}$. We get

$$
V_{i}\left(b_{i, t-s, t-1}\right)=\max _{c_{i, t-s, t}}\left\{\ln c_{i, t-s, t}+\beta(1-D) \mathrm{E}_{t} V_{i}\left(\frac{R_{t-1}(1+D)}{\Pi_{p, t}} b_{i, t-s, t-1}-c_{i, t-s, t}\right)\right\} .
$$

The FOC w.r.t. consumption implies

$$
\begin{aligned}
\frac{1}{c_{i, t-s, t}} & =\beta(1-D) \mathrm{E}_{t} V_{i}^{\prime}\left(\frac{R_{t-1}(1+D)}{\Pi_{p, t}} b_{i, t-s, t-1}-c_{i, t-s, t}\right) \\
& =\beta(1-D) \mathrm{E}_{t} V_{i}^{\prime}\left(b_{i, t-s, t}\right) .
\end{aligned}
$$

This equation implicitly gives us the optimal consumption for a given state, $b_{i, t-s, t-1}$. I represent this dependence by the function $c_{i}^{*}\left(b_{i, t-s, t-1}\right)$. Substituting this function back into the objective, we obtain

$$
V_{i}\left(b_{i, t-s, t-1}\right)=\ln c_{i}^{*}\left(b_{i, t-s, t-1}\right)+\beta(1-D) \mathrm{E}_{t} V_{i}\left(\frac{R_{t-1}(1+D)}{\Pi_{p, t}} b_{i, t-s, t-1}-c_{i}^{*}\left(b_{i, t-s, t-1}\right)\right)
$$

Applying Benveniste and Scheinkman (1979), i.e. taking the derivative w.r.t. $b_{i, t-s, t-1}$, noting that $c_{i}^{* \prime}\left(b_{i, t-s, t-1}\right)=0$, and using the FOC w.r.t. consumption yields

$$
\begin{aligned}
V_{i}^{\prime}\left(b_{i, t-s, t-1}\right) & =\frac{1}{c_{i}^{*}\left(b_{i, t-s, t-1}\right)} c_{i}^{* \prime}\left(b_{i, t-s, t-1}\right)+\beta \mathrm{E}_{t} V_{i}^{\prime}\left(b_{i, t-s, t}\right)\left(\frac{R_{t-1}(1+D)}{\Pi_{p, t}}-c_{i}^{* \prime}\left(b_{i, t-s, t-1}\right)\right) \\
& =\beta(1-D) \mathrm{E}_{t} V_{i}^{\prime}\left(b_{i, t-s, t}\right) \frac{R_{t-1}(1+D)}{\Pi_{p, t}} \\
& =\frac{1}{c_{i, t-s, t}} \frac{R_{t-1}(1+D)}{\Pi_{p, t}} .
\end{aligned}
$$


Iterating forward this result by one period and substituting into the FOC w.r.t. consumption yields

$$
\frac{1}{c_{i, t-s, t}}=\beta(1-D) \mathrm{E}_{t} \frac{R_{t}(1+D)}{\Pi_{p, t+1}} \frac{1}{c_{i, t-s, t+1}}
$$

which is the well-known Euler equation for consumption. Iteratively substituting forward leads to

$$
\frac{1}{c_{i, t-s, t}}=(\beta(1-D))^{n} \mathrm{E}_{t} \prod_{k=1}^{n} \frac{R_{t+k-1}(1+D)}{\Pi_{p, t+k}} \frac{1}{c_{i, t-s, t+n}} .
$$

Having obtained the FOCs of the inactive household, we can now derive a relation between consumption and wealth. To achieve this, we consider the beginning-of-period wealth in $t$ for the newly inactive household which does not yet participate in the insurance, i.e., $R_{t-1} / \Pi_{p, t} b_{i, t-s, t-1}=$ $R_{t-1} / \Pi_{p, t} b_{a, t-1}$ for $s=0$, We also consider the beginning-of-period wealth in $t$ for the inactive household which has been inactive before, i.e. $R_{t-1}(1+D) / \Pi_{p, t} b_{i, t-s, t-1}$ for $s=1,2, \ldots, \infty$. Iterating forward

$$
b_{i, t-s, t-1}=\left(\frac{R_{t-1}(1+D)}{\Pi_{p, t}}\right)^{-1} b_{i, t-s, t}+\left(\frac{R_{t-1}(1+D)}{\Pi_{p, t}}\right)^{-1} c_{i, t-s, t},
$$

recursively substituting into the budget constraint and using the FOC w.r.t. consumption yields for the newly inactive household

$$
\begin{aligned}
\frac{R_{t-1}}{\Pi_{p, t}} b_{a, t-1} & =b_{i, t, t}+c_{i, t, t} \\
& =\left(\frac{R_{t}(1+D)}{\Pi_{p, t+1}}\right)^{-1} b_{i, t, t+1}+\left(\frac{R_{t}(1+D)}{\Pi_{p, t+1}}\right)^{-1} c_{i, t, t+1}+c_{i, t-s, t} \\
& =\sum_{n=0}^{\infty} \prod_{k=1}^{n}\left(\frac{R_{t+k-1}(1+D)}{\Pi_{p, t+k}}\right)^{-1} c_{i, t, t+n} \\
& =\sum_{n=0}^{\infty} \prod_{k=1}^{n}\left(\frac{R_{t+k-1}(1+D)}{\Pi_{p, t+k}}\right)^{-1} c_{i, t, t+n}(\beta(1-D))^{n} \mathrm{E}_{t} \prod_{k=1}^{n} \frac{R_{t+k-1}(1+D)}{\Pi_{p, t+k}} \frac{1}{c_{i, t, t+n}} c_{i, t, t} \\
& =\sum_{n=0}^{\infty}(\beta(1-D))^{n} c_{i, t, t} \\
& =\frac{1}{1-\beta(1-D)} c_{i, t, t} \\
c_{i, t, t} & =\kappa \frac{R_{t-1}}{\Pi_{p, t}} b_{a, t-1}
\end{aligned}
$$

where $\kappa=(1-\beta(1-D))$. By the same reasoning, it is easy to see that the inactive household which has been inactive before and starts off period $t$ with wealth $R_{t-1}(1+D) / \Pi_{p, t} b_{i, t-s, t-1}$ for $s=1,2, \ldots, \infty$ chooses consumption proportional to its wealth, in particular,

$$
c_{i, t-s, t}=\kappa(1+D) \frac{R_{t-1}}{\Pi_{p, t}} b_{i, t-s, t-1} .
$$

Hence, the inactive household's choice of consumption is proportional to its previous wealth. 
Active households. The active household faces a risk $U$ of permanent income loss. We assume that households cannot loose income and die in the same period. Since we will assume a transfer ensuring that all active households have the same wealth independent from when they were born, we drop the $t-s$ subscript for active households. It is convenient to set up the household's problem of choosing consumption $c_{a, t}$, labor supply $n_{t}$ and wealth $b_{a, t}$ as a dynamic program:

$$
\begin{gathered}
V_{a}\left(b_{a, t-1}\right)=\max _{c_{a, t}, n_{t}}\left\{\ln c_{a, t}-\psi \frac{n_{t}^{1+\eta}}{1+\eta}+\beta(1-U) \mathrm{E}_{t} V_{a}\left(b_{a, t}\right)+\beta U \mathrm{E}_{t} V_{i}\left(b_{a, t}\right)\right\} \\
\text { s.t. } \quad c_{a, t}+b_{a, t}=\omega_{t}\left(1-u_{t}\right) n_{t}+\pi_{d, t}-t_{t}-\tau_{t}+\frac{R_{t-1}}{\Pi_{p, t}} b_{a, t-1}
\end{gathered}
$$

where $\psi$ and $\eta$ are a labor supply scaling parameter and the inverse of the Frisch elasticity, respectively. $\omega_{t}, u_{t}, \pi_{d, t}$, and $t_{t}$ denote the real wage, the unemployment rate, distributed profits, and a lump-sum government tax. Note that we assume that every household is affected by unemployment to the same extent. The variable $\tau_{t}$ needs some clarification (cf. Carroll and Jeanne 2009): A natural consequence of the population dynamics assumed is that the stock of wealth increases with the age of the household. To simplify aggregation, we assume a transfer from non-newborn to newborn household which ensures that wealth is distributed equally across active households at any point in time. A newborn household receives a transfer of $b_{a, t}-\tau_{t}$. The non-newborn household must give away $\tau_{t}$ of its wealth. The crucial implication of this transfer is that both newborn and nonnewborn households face the same budget constraint after the transfer. Assuming that the transfer is financed by a tax on wealth, i.e. $\tau_{t}=\tau b_{a, t}$, the required tax rate can be shown to be $\tau=U$. This follows from the fact that the payments aggregated over all non-newborn active households with mass $1 / U-1$ must equal the receipts aggregated over all newborn active households with mass one, i.e. $(1 / U-1) \tau b_{a, t}=b_{a, t}-\tau b_{a, t}$. Note that $V_{a}\left(b_{a, t-1}\right)$ is the value function in $t$ and $b_{a, t-1}$ the state variable. Note further that $V_{i}\left(b_{a, t}\right)$ is the $t+1$ value function of a household that became inactive at the beginning of $t+1$. Before solving this problem let us substitute out $b_{a, t}$. We get

$$
V_{a}\left(b_{a, t-1}\right)=\max _{c_{a, t}, n_{t}}\left\{\begin{array}{c}
\ln c_{a, t}-\psi \frac{n_{t}^{1+\eta}}{1+\eta}+ \\
+\beta(1-U) \mathrm{E}_{t} V_{a}\left(\omega_{t}\left(1-u_{t}\right) n_{t}+\pi_{d, t}-t_{t}-\tau_{t}+\frac{R_{t-1}}{\Pi_{p, t}} b_{a, t-1}-c_{a, t}\right)+ \\
+\beta U \mathrm{E}_{t} V_{i}\left(\omega_{t}\left(1-u_{t}\right) n_{t}+\pi_{d, t}-t_{t}-\tau_{t}+\frac{R_{t-1}}{\Pi_{p, t}} b_{a, t-1}-c_{a, t}\right)
\end{array}\right\}
$$

The FOC w.r.t. consumption implies

$$
\begin{aligned}
\frac{1}{c_{a, t}} & =\beta(1-U) \mathrm{E}_{t} V_{a}^{\prime}\left(\omega_{t}\left(1-u_{t}\right) n_{t}+\pi_{d, t}-t_{t}-\tau_{t}+\frac{R_{t-1}}{\Pi_{p, t}} b_{a, t-1}-c_{a, t}\right)+ \\
& +\beta U \mathrm{E}_{t} V_{i}^{\prime}\left(\omega_{t}\left(1-u_{t}\right) n_{t}+\pi_{d, t}-t_{t}-\tau_{t}+\frac{R_{t-1}}{\Pi_{p, t}} b_{a, t-1}-c_{a, t}\right) \\
& =\beta(1-U) \mathrm{E}_{t} V_{a}^{\prime}\left(b_{a, t}\right)+\beta U \mathrm{E}_{t} V_{i}^{\prime}\left(b_{a, t}\right) .
\end{aligned}
$$

This equation implicitly gives us the optimal consumption for a given state, $b_{a, t-1}$. We represent this dependence by the function $c_{a}^{*}\left(b_{a, t-1}\right)$. Substituting this function back into the objective, we 
obtain

$$
V_{a}\left(b_{a, t-1}\right)=\left\{\begin{array}{c}
\ln c_{a}^{*}\left(b_{a, t-1}\right)-\psi \frac{n_{t}^{1+\eta}}{1+\eta}+ \\
+\beta(1-U) \mathrm{E}_{t} V_{a}\left(\omega_{t}\left(1-u_{t}\right) n_{t}+\pi_{d, t}-t_{t}-\tau_{t}+\frac{R_{t-1}}{\Pi_{p, t}} b_{a, t-1}-c_{a}^{*}\left(b_{a, t-1}\right)\right)+ \\
+\beta U \mathrm{E}_{t} V_{i}\left(\omega_{t}\left(1-u_{t}\right) n_{t}+\pi_{d, t}-t_{t}-\tau_{t}+\frac{R_{t-1}}{\Pi_{p, t}} b_{a, t-1}-c_{a}^{*}\left(b_{a, t-1}\right)\right)
\end{array}\right\}
$$

Following Benveniste and Scheinkman (1979), i.e. taking the derivative w.r.t. $b_{a, t-1}$, noting that $c_{a}^{* \prime}\left(b_{a, t-1}\right)=0$, and using the FOC w.r.t. consumption yields

$$
\begin{aligned}
V_{a}^{\prime}\left(b_{a, t-1}\right) & =\frac{1}{c_{a}^{*}\left(b_{a, t-1}\right)} c_{a}^{* \prime}\left(b_{a, t-1}\right)+ \\
& +\beta(1-U) \mathrm{E}_{t} V_{a}^{\prime}\left(b_{a, t}\right)\left(\frac{R_{t-1}}{\Pi_{p, t}}-c_{a}^{* \prime}\left(b_{a, t-1}\right)\right)+\beta U \mathrm{E}_{t} V_{i}^{\prime}\left(b_{a, t}\right)\left(\frac{R_{t-1}}{\Pi_{p, t}}-c_{a}^{* \prime}\left(b_{a, t-1}\right)\right) \\
& =\beta(1-U) \mathrm{E}_{t} V_{a}^{\prime}\left(b_{a, t}\right) \frac{R_{t-1}}{\Pi_{p, t}}+\beta U \mathrm{E}_{t} V_{i}^{\prime}\left(b_{a, t}\right) \frac{R_{t-1}}{\Pi_{p, t}} \\
& =\frac{1}{c_{a, t}} \frac{R_{t-1}}{\Pi_{p, t}}
\end{aligned}
$$

Iterating forward this result as well as the previous result for the inactive household $V_{i}^{\prime}\left(b_{i, t, t-1}\right)=$ $\frac{1}{c_{i, t, t}} \frac{R_{t-1}}{\Pi_{p, t}}$ by one period and substituting into the FOC w.r.t. consumption yields

$$
\begin{aligned}
\frac{1}{c_{a, t}} & =\beta \mathrm{E}_{t} \frac{R_{t}}{\Pi_{p, t+1}}\left((1-U) \frac{1}{c_{a, t+1}}+U \frac{1}{c_{i, t+1, t+1}}\right) \\
\frac{1}{c_{a, t}} & =\beta(1-U) \mathrm{E}_{t} \frac{R_{t}}{\Pi_{p, t+1}} \frac{1}{c_{a, t+1}}+\beta U \frac{1}{\kappa b_{a, t}}
\end{aligned}
$$

where the last line uses the FOC of the newly inactive household. The expected marginal utility of consumption in $t+1$ takes into account the risk of income loss.

After using the FOC w.r.t. consumption, the FOC w.r.t. labor supply implies

$$
\begin{aligned}
\psi n_{t}^{\eta} & =\beta(1-U) \mathrm{E}_{t} V_{a}^{\prime}\left(b_{a, t}\right) \omega_{t}\left(1-u_{t}\right)+\beta U \mathrm{E}_{t} V_{i}^{\prime}\left(b_{a, t}\right) \omega_{t}\left(1-u_{t}\right) \\
& =\frac{1}{c_{a, t}} \omega_{t}\left(1-u_{t}\right) .
\end{aligned}
$$

Aggregation. The inactive household's wealth $b_{i, t-s, t}$ depends on its age $s$ and on how much it brought over from the active state. Due to the FOC w.r.t. consumption, consumption will vary across households. Aggregation of a stock or flow variable $x_{i, t-s, t}$ of the inactive household is summing over all households. Noting that inactive households of age $s$ are a homogenous cohort of size $(1-D)^{s}$, we can define $X_{i, t} \equiv \sum_{s=0}^{\infty}(1-D)^{s} x_{i, t-s, t}$.

Using these definitions let us first aggregate the inactive households' budget constraints for period $t$. I first aggregate each cohort $s$ separately and then sum over the cohorts, as illustrated in Table 1. Note that, unlike households that have been inactive before, newly inactive households do not receive a payment from the insurance company. Since the size of the cohort is one and since the population of active households is $1 / U$, their initial wealth carried over from the active state is simply $U R_{t-1} / \Pi_{p, t} B_{a, t-1}$. Note further that the beginning-of-period $t$ wealth of all households 
Table 1: Aggregation over inactive households in period $t$.

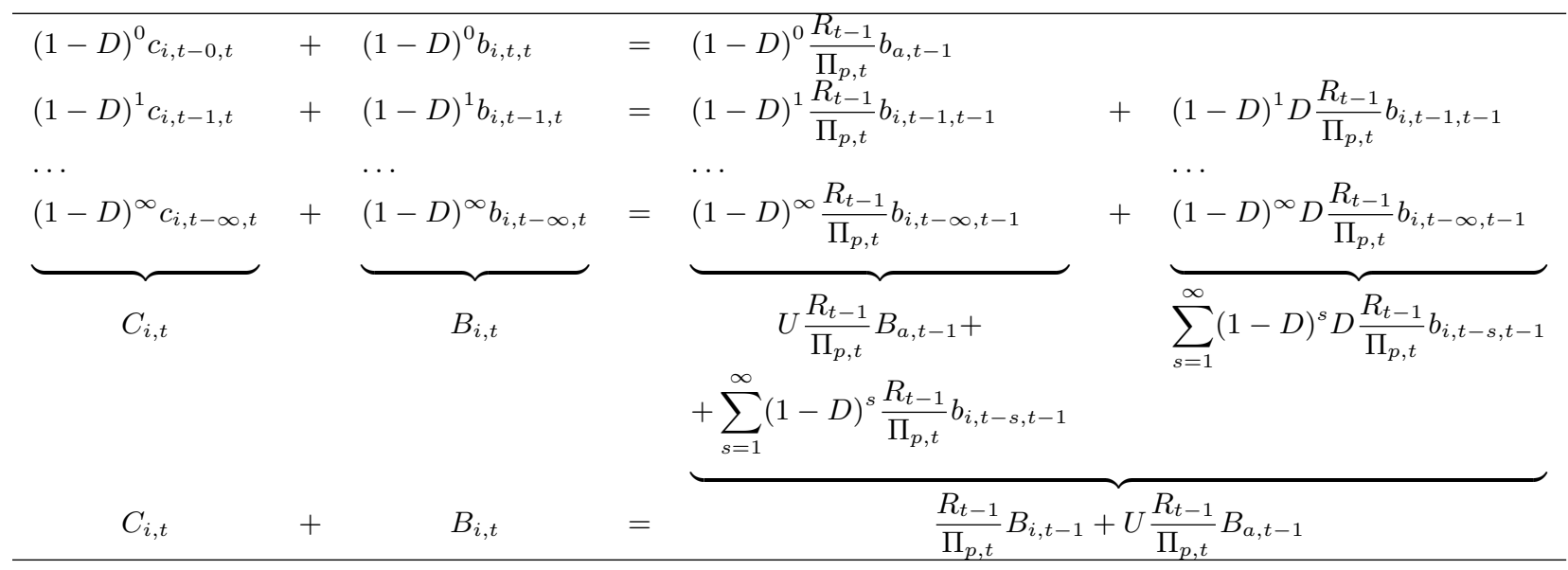

which have been inactive in $t-1$ and are still inactive in $t$ is the end-of-period $t-1$ wealth of all inactive households in $t-1$ plus the end-of-period $t-1$ wealth of the inactive households who died at the beginning of $t$. This wealth of the latter group (inactive in $t-1$ and died in $t$ ) is transferred to the former group (inactive in $t-1$ and still inactive in $t$ ) through the insurance company. After normalizing by the deterministic productivity trend $\Gamma^{t}$, we obtain the aggregated budget constraint of the inactive households as

$$
\begin{aligned}
C_{i, t}+B_{i, t} & =\frac{R_{t-1}}{\Pi_{p, t}}\left(B_{i, t-1}+U B_{a, t-1}\right) \\
\frac{C_{i, t}}{\Gamma^{t}}+\frac{B_{i, t}}{\Gamma^{t}} & =\frac{R_{t-1}}{\Pi_{p, t}}\left(\frac{B_{i, t-1}}{\Gamma^{t}}+U \frac{B_{a, t-1}}{\Gamma^{t}}\right) \\
\tilde{C}_{i, t}+\tilde{B}_{i, t} & =\frac{1}{\Gamma} \frac{R_{t-1}}{\Pi_{p, t}}\left(\tilde{B}_{i, t-1}+U \tilde{B}_{a, t-1}\right)
\end{aligned}
$$

The inactive household's FOC tells us that its period $t$ consumption will be proportional to its beginning-of-period wealth. Since the proportionality factor $\kappa$ is constant it can easily be verified that

$$
\tilde{C}_{i, t}=\kappa \frac{1}{\Gamma} \frac{R_{t-1}}{\Pi_{p, t}}\left(\tilde{B}_{i, t-1}+U \tilde{B}_{a, t-1}\right)
$$

Since active households hold identical stocks of wealth $b_{a, t}$ in any period $t$ independent of their age, aggregation of stocks and flows is simply $X_{a, t} \equiv 1 / U x_{a, t}$ for any variable $x_{a, t}$ of the active household in $t$, recalling that $1 / U$ is the mass of active households in every period $t$ as the inflow and outflow are the same. Recall further that beginning-of-period $t$ active wealth is end-of-period $t-1$ active wealth minus the wealth that became inactive at the beginning of $t$. Hence, the active households budget constraints can be aggregated as

$$
\tilde{C}_{a, t}+\tilde{B}_{a, t}=\tilde{Z}_{t}+(1-U) \frac{1}{\Gamma} \frac{R_{t-1}}{\Pi_{p, t}} \tilde{B}_{a, t-1}
$$


where

$$
\tilde{Z}_{t}=\tilde{\omega}_{t} L_{t}+\tilde{\Pi}_{d, t}-\tilde{T}_{t}
$$

is the active households' detrended aggregate real net income. Note that $L_{t}=\left(1-u_{t}\right) N$, which is implied by the definition of the unemployment rate

$$
1-u_{t}=\frac{L_{t}}{N_{t}}
$$

denotes labor input and $\tilde{\Pi}_{d, t}$ distributed profits by the intermediate good firms to be specified below. The aggregated FOC w.r.t. consumption is

$$
\frac{1}{\tilde{C}_{a, t}}=\beta(1-U) \frac{1}{\Gamma} \mathrm{E}_{t} \frac{R_{t}}{\Pi_{p, t+1}} \frac{1}{\tilde{C}_{a, t+1}}+\beta U \frac{1}{\kappa \tilde{B}_{a, t}}
$$

Aggregating over all households yields

$$
\tilde{C}_{t}=\tilde{C}_{a, t}+\tilde{C}_{i, t}
$$

Aggregation of the FOC w.r.t. labor supply leads to

$$
\psi U^{1+\eta} N_{t}^{\eta}=\frac{1}{\tilde{C}_{a, t}} \tilde{\omega}_{t}\left(1-u_{t}\right) .
$$

\section{$2.2 \quad$ Firms}

Final good firms. Taken as given price $p_{i, t}$, the final good firm's demand for the intermediate good $y_{i, t}$ supplied by intermediate good firm $i$ can be obtained from the following cost minimization problem:

$$
\begin{gathered}
\min _{y_{i, t}} \int_{0}^{1} p_{i, t} y_{i, t} d i \\
\text { s.t. } Y_{t}=\int_{0}^{1}\left(y_{i, t}^{\frac{\epsilon-1}{\epsilon}} d i\right)^{\frac{\epsilon}{\epsilon-1}},
\end{gathered}
$$

where $\epsilon>1$ is the elasticity of substitution. Noting that the Lagrangian multiplier of the constraint is equal to the aggregate price index, $P_{t}$, one can show the FOC to read

$$
y_{i, t}=\left(\frac{p_{i, t}}{P_{t}}\right)^{-\epsilon} Y_{t}
$$

Intermediate good firms. Taking as given total output $Y_{t}$, the overall price level $P_{t}$, and the wage rate $\omega_{t}$ as well as the law of motion of capital, the production function, the demand function for intermediate goods, and the requirement to maintain a debt-capital ratio $\lambda$, the firm $i$ chooses $\left\{p_{i, t}, l_{i, t}, i_{i, t}, k_{i, t}, d_{i, t}\right\}_{t=0}^{\infty}$ to maximize discounted inter-temporal distributed profits. Dropping the 
firm index for convenience and evaluating at period $t=0$, the optimization problem reads

$$
\begin{aligned}
\max _{\left\{p_{t}, l_{t}, i_{t}, k_{t}, d_{t}\right\}_{t=0}^{\infty}} & \mathrm{E}_{0} \sum_{t=0}^{\infty} \frac{P_{0}}{P_{t}} \Lambda_{0, t}\left[\begin{array}{r}
p_{t} y_{t}-w_{t} l_{t}-P_{t} i_{t}-P_{t} \frac{\tau_{i}}{2}\left(\frac{i_{t}}{\Gamma k_{t-1}}-\left(1-(1-\delta) \frac{1}{\Gamma}\right)\right)^{2} k_{t-1}- \\
-P_{t} \frac{\tau_{p}}{2} \Gamma^{t}\left(\frac{p_{t}}{p_{t-1}}-\Pi\right)^{2}+P_{t} d_{t}-R_{t-1} P_{t-1} d_{t-1}
\end{array}\right] \\
\text { s.t. } \quad k_{t} & =i_{t}+(1-\delta) k_{t-1} \\
y_{t} & =V_{A, t}\left(\Gamma k_{t-1}\right)^{\alpha}\left(\Gamma^{t} l_{t}\right)^{1-\alpha} \\
y_{t} & =\left(\frac{p_{t}}{P_{t}}\right)^{-\epsilon} Y_{t} \\
d_{t} & =\lambda q_{t} k_{t}
\end{aligned}
$$

where $i_{i, t}, k_{i, t}, d_{i, t}, V_{A, t}$, and $q_{t}$ are investment, the capital stock, outstanding bonds, total factor productivity, and the price of capital, respectively. $\tau_{i}, \delta, \tau_{p}$, and $\alpha$ denote the capital adjustment costs scaling parameter, the rate of capital depreciation, the price adjustment costs scaling parameter, and the capital elasticity of production. $\Lambda_{t, t+j}$ is the stochastic discount factor which expresses the value of a unit real profit in time $t+j$ in terms of the value of a unit real profit in time $t$. Note that the definition of the stochastic discount factor implies that $\mathrm{E}_{t} \frac{R_{t}}{\Pi_{p, t+1}} \Lambda_{t, t+1}=1$. Then, the FOC w.r.t. $d_{t}$ is

$$
\begin{aligned}
\frac{P_{t}}{P_{t}} \Lambda_{t, t} P_{t}+\frac{P_{t}}{P_{t}} \Lambda_{t, t} P_{t} \mu_{t}-\mathrm{E}_{t} \frac{P_{t}}{P_{t+1}} \Lambda_{t, t+1} R_{t} P_{t} & =0 \\
1+\mu_{t}-\mathrm{E}_{t} \frac{R_{t}}{\Pi_{p, t+1}} \Lambda_{t, t+1} & =0 \\
\mu_{t} & =0 .
\end{aligned}
$$

The financial structure of the firm is irrelevant from the household's perspective. Regarding the price decision, note that all firms charge the same price, $p_{t}=P_{t}$, and, hence $y_{t}=Y_{t}$ with a mass one of firms. The FOC w.r.t. $p_{t}$ then implies

$$
\begin{array}{r}
(1-\epsilon) y_{t}-P_{t} \tau_{p} \Gamma^{t}\left(\frac{p_{t}}{p_{t-1}}-\Pi\right) \frac{1}{p_{t-1}}+\epsilon P_{t} \varphi_{t} \frac{y_{t}}{p_{t}}+ \\
+\mathrm{E}_{t} \frac{P_{t}}{P_{t+1}} \Lambda_{t, t+1} P_{t+1} \tau_{p} \Gamma^{t+1}\left(\frac{p_{t+1}}{p_{t}}-\Pi\right) \frac{p_{t+1}}{p_{t}^{2}}=0 \\
\left((\epsilon-1)-\epsilon \varphi_{t}\right) \tilde{Y}_{t}+\tau_{p}\left(\Pi_{t}-\Pi\right) \Pi_{t}-\mathrm{E}_{t} \Lambda_{t, t+1} \tau_{p} \Gamma\left(\Pi_{p, t+1}-\Pi\right) \Pi_{p, t+1}=0
\end{array}
$$

where

$$
\mathrm{E}_{t} \Lambda_{t, t+1}=\beta \mathrm{E}_{t} \frac{(1-U) c_{a, t+1}^{-1}+U(1+D) c_{i, t+1, t+1}^{-1}}{c_{a, t}^{-1}}=\mathrm{E}_{t}\left(\frac{R_{t}}{\Pi_{p, t+1}}\right)^{-1} .
$$

To derive the implications of the FOC w.r.t. $l_{t}$ first note that the production function can be rewritten as $\left(\frac{y_{t}}{\Gamma k_{t-1}} \frac{1}{V_{A, t}}\right)^{\frac{\alpha}{1-\alpha}}=\left(\frac{\Gamma k_{t-1}}{\Gamma^{t} l_{t}}\right)^{-\alpha}$. Then,

$$
\begin{aligned}
-w_{t}+P_{t} \varphi_{t} V_{A, t} \Gamma^{t(1-\alpha)}(1-\alpha) l_{t}^{-\alpha}\left(\Gamma k_{t-1}\right)^{\alpha} & =0 \\
\varphi_{t} & =\tilde{\omega}_{t} \frac{1}{1-\alpha}\left(\frac{1}{V_{A, t}}\right)^{\frac{1}{1-\alpha}}\left(\frac{\tilde{Y}_{t}}{\tilde{K}_{t-1}}\right)^{\frac{\alpha}{1-\alpha}} .
\end{aligned}
$$


The FOC w.r.t to $i_{t}$ implies

$$
\begin{gathered}
-P_{t}-P_{t} \tau_{i}\left(\frac{i_{t}}{\Gamma k_{t-1}}-\left(1-(1-\delta) \frac{1}{\Gamma}\right)\right) \frac{1}{\Gamma k_{t-1}} k_{t-1}+P_{t} q_{t}=0 \\
q_{t}=1+\tau_{i} \frac{1}{\Gamma}\left(\frac{\tilde{I}_{t}}{\tilde{K}_{t-1}}-\left(1-(1-\delta) \frac{1}{\Gamma}\right)\right)
\end{gathered}
$$

Recalling that $\mu_{t}=0$ and noting that $\frac{y_{t}}{\Gamma k_{t-1}}=V_{A, t}\left(\frac{\Gamma k_{t-1}}{\Gamma^{t} l_{t}}\right)^{\alpha-1}$, the FOC w.r.t. $k_{t}$ implies

$$
\begin{gathered}
P_{t} q_{t}+P_{t} \mu_{t+1} \lambda q_{t}=\mathrm{E}_{t} \frac{P_{t}}{P_{t+1}} \Lambda_{t, t+1}\left[\begin{array}{c}
P_{t+1} \tau_{i}\left(\frac{i_{t+1}}{\Gamma k_{t}}-\left(1-(1-\delta) \frac{1}{\Gamma}\right)\right) \frac{i_{t+1}}{\Gamma k_{t}}- \\
-P_{t+1} \frac{\tau_{i}}{2}\left(\frac{i_{t+1}}{\Gamma k_{t}}-\left(1-(1-\delta) \frac{1}{\Gamma}\right)\right)^{2}+ \\
+P_{t+1} \varphi_{t+1} \alpha V_{A, t+1}\left(\Gamma k_{t}\right)^{\alpha-1}\left(\Gamma^{t} l_{t+1}\right)^{1-\alpha}+P_{t+1} q_{t+1}(1-\delta)
\end{array}\right] \\
q_{t}=\mathrm{E}_{t} \Lambda_{t, t+1}\left[\begin{array}{c}
\tau_{i}\left(\frac{\tilde{I}_{t+1}}{\tilde{K}_{t}}-\left(1-(1-\delta) \frac{1}{\Gamma}\right)\right) \frac{\tilde{I}_{t+1}}{\tilde{K}_{t}}-\frac{\tau_{i}}{2}\left(\frac{\tilde{I}_{t+1}}{\tilde{K}_{t}}-\left(1-(1-\delta) \frac{1}{\Gamma}\right)\right)^{2}+ \\
+\varphi_{t+1} \alpha \frac{\tilde{Y}_{t+1}}{\tilde{K}_{t}}+q_{t+1}(1-\delta)
\end{array}\right] .
\end{gathered}
$$

Aggregating the law of motion of the capital stock leads to

$$
\tilde{K}_{t}=\tilde{I}_{t}+(1-\delta) \frac{1}{\Gamma} \tilde{K}_{t-1}
$$

The production function can be aggregated as follows. Note that all firms set the same price, $p_{t}=P_{t}$.

$$
\tilde{Y}_{t}=V_{A, t} \tilde{K}_{t-1}^{\alpha} L_{t}^{1-\alpha} .
$$

Recalling that firms maintain a debt-capital ratio of $\lambda$, the aggregated detrended real distributed profits are

$$
\tilde{\Pi}_{d, t}=\tilde{Y}_{t}-\tilde{\omega}_{t} L_{t}-(1-\lambda) \tilde{I}_{t}-\frac{\tau_{i}}{2} \frac{1}{\Gamma}\left(\frac{\tilde{I}_{t}}{\tilde{K}_{t-1}}-\left(1-(1-\delta) \frac{1}{\Gamma}\right)\right)^{2} \tilde{K}_{t-1}-\frac{\tau_{p}}{2}\left(\Pi_{p, t}-\Pi\right)^{2} .
$$

The growth rate of the real wage is linked to wage and price inflation according to

$$
\frac{\tilde{\omega}_{t}}{\tilde{\omega}_{t-1}}-1=\Pi_{w, t}-\Pi_{p, t}
$$

\subsection{The labor market}

We assume that the rate of wage inflation is subject to a bargaining process between a workers' and a firms' representative. The respective return functions are crucial for the bargaining game. We take the steady-state real wage $\tilde{\omega}$ which can be computed for a given wage inflation $\Pi^{w, t}$, i.e., $\tilde{\omega}\left(\Pi^{w, t}\right)$, as the worker's return and the steady-state profit rate, $r\left(\Pi^{w, t}\right)$, as the firm's return. Due to the presence of price adjustment costs, the former can be shown to increase and the latter to decrease in the rate of wage inflation. Hence, we suggest that the bargaining parties are concerned 
with the long-run implications of the bargaining. By assuming that the state of the labor market affects the relative bargaining power, however, the rate of wage inflation will be cyclical. The bargaining game reads

$$
\max _{\Pi_{w, t}}\left(\tilde{\omega}\left(\Pi_{w, t}\right)\right)^{\nu_{t}}\left(r\left(\Pi_{w, t}\right)\right)^{1-\nu_{t}}
$$

where $\tilde{\omega}(\cdot)$ and $r(\cdot)$ are the steady states of the real wage and the profit rate, respectively, as functions of the wage inflation and $v_{t}$ is the worker's relative bargaining power. The FOC of this problem determines the rate of nominal wage inflation, $\Pi_{w, t}$, and reads

$$
1=\left(1-1 / \nu_{t}\right) \frac{\tilde{\omega}\left(\Pi_{w, t}\right)}{r\left(\Pi_{w, t}\right)} \frac{r^{\prime}\left(\Pi_{w, t}\right)}{\tilde{\omega}^{\prime}\left(\Pi_{w, t}\right)}
$$

where

$$
\frac{\nu_{t}}{\nu}=\left(\frac{1-u_{t}}{1-u}\right)^{\phi_{u}}
$$

Note that there is not feedback of the labor market to wage formation if $\phi_{u}=0$. In this case, the rate of wage inflation is constant.

\section{$2.4 \quad$ Fiscal and monetary policy}

For all models we assume the government budget to be balanced at all times and monetary policy to follow a Taylor rule:

$$
\begin{aligned}
& \tilde{T}_{t}=\tilde{G} \\
& \frac{R_{t}}{R}=\left(\frac{\Pi_{p, t}}{\Pi}\right)^{\phi_{r \pi}} V_{R, t}
\end{aligned}
$$

\subsection{Goods market clearing}

As can easily be verified, aggregating over all budget constraints leads to the macro-economic balance condition,

$$
\tilde{Y}_{t}=\tilde{C}_{t}+\tilde{I}_{t}+\tilde{G}+\frac{\tau_{i}}{2} \frac{1}{\Gamma}\left(\frac{\tilde{I}_{t}}{\tilde{K}_{t-1}}-\left(1-(1-\delta) \frac{1}{\Gamma}\right)\right)^{2} \tilde{K}_{t-1}+\frac{\tau_{p}}{2}\left(\Pi_{p, t}-\Pi\right)^{2} .
$$

\subsection{Exogenous processes}

The monetary policy shock and total factor productivity shock are assumed to evolve according to

$$
\begin{aligned}
& V_{R, t}=V_{R, t-1}^{\rho_{R}} \exp \varepsilon_{R, t}, \\
& V_{A, t}=V_{A, t-1}^{\rho_{A}} \exp \varepsilon_{A, t},
\end{aligned}
$$

where $\varepsilon_{R, t} \sim$ i.i.d.N $(0,1)$ and $\varepsilon_{A, t} \sim$ i.i.d. $\mathcal{N}(0,1)$ are exogenous innovations. 


\section{Model implications}

The precautionary saving motive in the household's behavior combined with the assumption of non-accommodating collective wage bargaining instead of accommodating wage adjustment have vast implications for the model characteristics and, in particular, the nature of unemployment. Let us briefly contrast the model implications to those of a corresponding DSGE model with labor market clearing.

Demand-driven adjustment. Without the assumption of an accommodating nominal wage and with consumption depending on current income, the DSDE model has a strong Keynesian character. This is because we have left the realm of general equilibrium theory. The nominal wage does not adjust to eliminate any disequilibrium going beyond frictional unemployment. Removing any frictions and rigidities would eliminate unemployment in a DSGE model but not in the DSDE model. Since labor is not fully employed and involuntary non-frictional unemployment persists in the steady state, the resource constraint known from DSGE models now has the interpretation of a goods market equilibrium condition stating that aggregate output needs to equal aggregate spending.

In DSGE models business fluctuations are supply-driven. This means that output changes to shocks mediated by equilibrium adjustments on the factor markets. Nevertheless, aggregate demand shocks play a role. Consider a government shock. Both demand and output will increase and unemployment will drop. This is because, given product and labor market frictions as well as price and wage setting rigidities, the rise in demand will cause a possible staggered wage and price adjustment such that agents find it beneficial to provide more resources. Aggregate demand is limited by resources brought to the market, i.e. supply, at any period of time. Put in different words, demand shocks would not alter output if, for some reason, the supply side of the factor markets stayed constant. This is the essence of supply-driven fluctuations. In the DSDE model business fluctuations are demand-driven. A demand shock affects output without requiring households to provide more resources since at the given real wage labor is unemployed even in the absence of frictions and rigidities. Nevertheless, supply shocks do have effects on demand and output which addresses the criticism by Michaillat and Saez (2014) of disequilibrium models. This is because of the labor market feedback on the wage formation. As labor market conditions change after a supply shock, so does the relative bargaining power and, hence, the nominal rate of wage inflation which, then, affects demand.

The natural rate of interest. The steady-state implications for the interest rate differ fundamentally between DSDE and DSGE models. Let us consider a simple DSGE model with labor market clearing which can be obtained from the DSDE model by setting $U=0$ and $u_{t}=0$. For a steady state to exist, the household's Euler equation requires the steady-state real interest rate to be equal to the inverse of the discount factor referred to as the natural rate of interest, i.e. $R / \Pi=1 / \beta$. For a given inflation target, $\Pi$, in the monetary policy rule $(21)$, the natural rate implies the steady-state nominal rate as $R=\Pi / \beta$. The monetary authority's target interest rate $R$ in (21) needs to equal this nominal rate as a steady state condition. Now, consider a rise in the steady-state inflation rate $\Pi$. This will require the nominal interest rate $R$ to increase accordingly for the natural interest rate to remain constant and equal to the inverse discount rate.

This allows us to understand why the DSDE model needs a Keynesian type of relation be- 
tween consumption and income which we have introduced by exposing the households to a risk of permanent income loss. Consider a simple DSGE model without precautionary saving. The Euler equation requires $R / \Pi=1 / \beta$. Let us now obtain the corresponding DSDE model. We start by dropping the assumption of labor-market clearing $u_{t}=0$, which eliminates one equation of the system and renders the steady state indeterminate. Then, we introduce a policy rule (or bargaining solution) governing the evolution of the wage inflation, which adds one equation to the system, say $\Pi_{w, t}=\Pi_{w}$ for the sake of the argument. Unfortunately, the steady state is still indeterminate. To see this, note that the monetary authority's price inflation target needs to be consistent with the steady state of the wage inflation rule, i.e., $\Pi=\Pi_{w}$, in order for the real wage to be constant at the steady state. As explained above, a change in the inflation target of the central bank only affects the steady state of the interest rate in the DSGE model due to the parameter restrictions implied by the Euler equation, but not the steady states of the other variables. Hence, the wage inflation rule cannot be considered an additional independent equation, since the steady-state restriction $\Pi=\Pi_{w}$ needs to be maintained.

Now, consider a DSGE model with precautionary saving or, in other words, a DSDE model with $u_{t}=0$ instead of the wage formation rule. At the steady state, the consumption Euler equation (of the active household) looks very different from the previous case. Consumption does not cancel out but is now related to wealth and the real interest rate. Hence, the Euler equation does not impose a steady state restriction for the real interest rate. Rather than that, the real interest rate is restricted by the entire system, In particular, it is restricted such that the labor market clears at a given target inflation rate $\Pi$ which, at the steady state, the wage inflation rate $\Pi_{w}$ has to be equal to. Hence, since $\Pi=\Pi_{w}$ is a steady-state restriction, $\Pi_{w}$ is not free to clear the labor market at a given real interest rate. Rather, the natural rate is now defined as the real interest rate which clears the labor market at a given $\Pi_{w}=\Pi$. Suppose the central bank changes the target inflation rate $\Pi$ in this model. This has no real steady state effects in the standard DSGE model as the central bank will modify the target interest rate $R$ accordingly in order to keep the real interest rate constant at $1 / \beta$, i.e., the natural rate which stays unchanged. Yet, in the precautionary saving DSGE model, a change in $\Pi$ and, hence, $\Pi_{w}$ modifies the natural interest rate due to the presence of price adjustment costs. With a different $\Pi$, the natural rate $R / \Pi$ which clears the labor market at a given $\Pi_{w}$ will also be different. To summarize, in the precautionary DSGE model, steady state restrictions are such that the real interest rate adjusts to clear labor market for a given wage inflation rate. In other words, fixing the interest rate at a level such that the real interest rate is not equal to the natural interest rate, the model is overdetermined, as the zero unemployment equation would be violated.

In the DSDE model, we fix the steady-state real interest rate for a given wage inflation rate at a level different form the natural rate, but we drop the assumption of labor market clearing. Hence, the steady state is determinate.

Dynamic efficiency. In the conventional Ramsey model, Pareto efficiency of the inter-temporal allocation of savings is guaranteed by the transversality condition which requires that the interest rate exceeds the growth rate. A similar condition has to hold for dynamic efficiency in the standard overlapping generations framework. In the DSDE model, the criterion of Pareto efficiency does not apply as resources are under-utilized in equilibrium. Consequently, the economy is dynamically inefficient regardless of the relation between the interest rate and the growth rate. Rather than efficiency considerations, it is the precautionary saving motive which imposes a restriction on the 


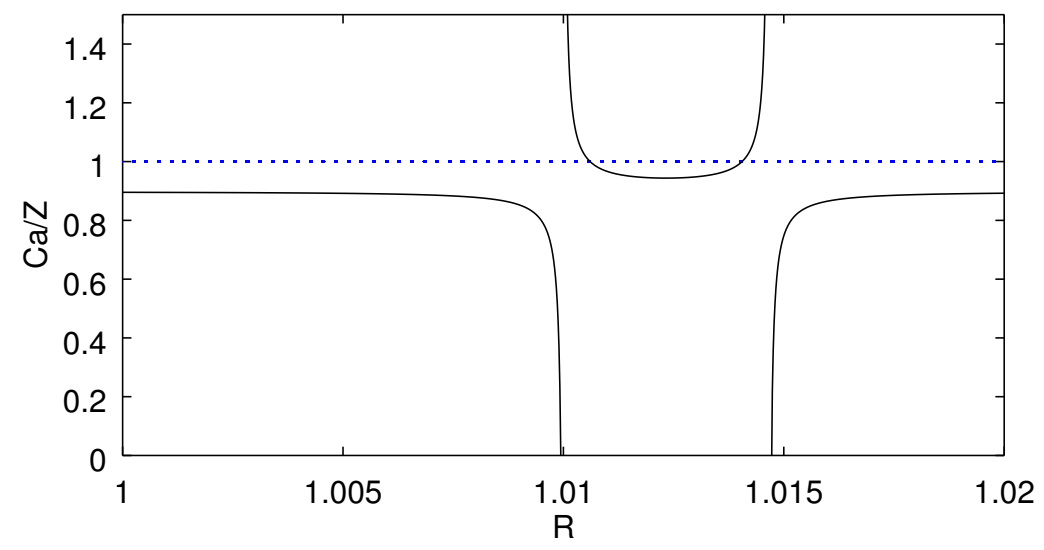

(a) Consumption-income ratio of active households

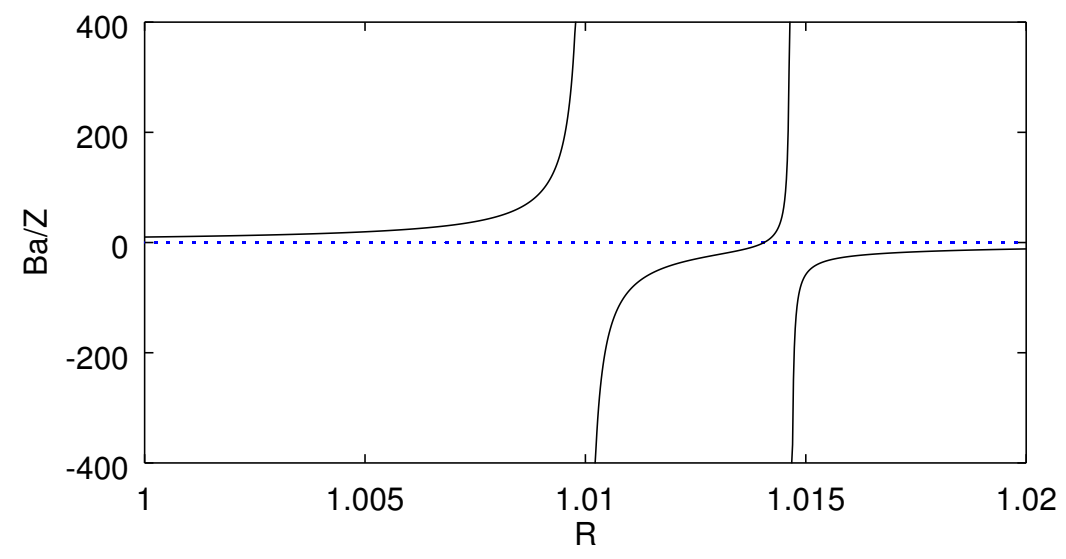

(b) Wealth-income ratio of active households

Figure 1: Steady-state values of the consumption-income and wealth income ratios of the active households for different interest rates.

interest rate. For a sensible steady state to exist, the real interest rate has to be lower than the growth rate, $R / \Pi<\Gamma$. The intuition behind this is that otherwise, in equilibrium, the stock of wealth would grow faster than income. Note that this is in stark contrast to the dynamic efficiency requirement of conventional DSGE models.

Figure 1 plots the equilibrium values of the consumption-income ratio (upper panel) and wealthincome ratio (lower panel) of active households for different interest rates and, otherwise, the calibration reported in Appendix A. ${ }^{6}$ Only for the range that the interest rate is lower than the growth rate, $R<\Gamma=1.01$, do the steady states of $\tilde{C}_{a} / Z$ and $\tilde{B}_{a} / Z$ make economic sense. For $R \geq \Gamma$, either $\tilde{C}_{a} / Z$ or $\tilde{B}_{a} / Z$ or both are negative.

Equilibrium determinacy. As is well known for the DSGE literature, the Taylor principle states that, in response to inflationary pressures, the monetary authority needs to raise the interest

\footnotetext{
${ }^{6} \mathrm{I}$ assume that $\theta, \alpha, \psi$, and $\nu$ adjust such that, after a change in $R$, we maintain $\tilde{Y}=1, \tilde{Y} / \tilde{K}=0.1, u=0$, and $\Pi_{w}=\Pi$, respectively. Note that $\Pi=1$.
} 


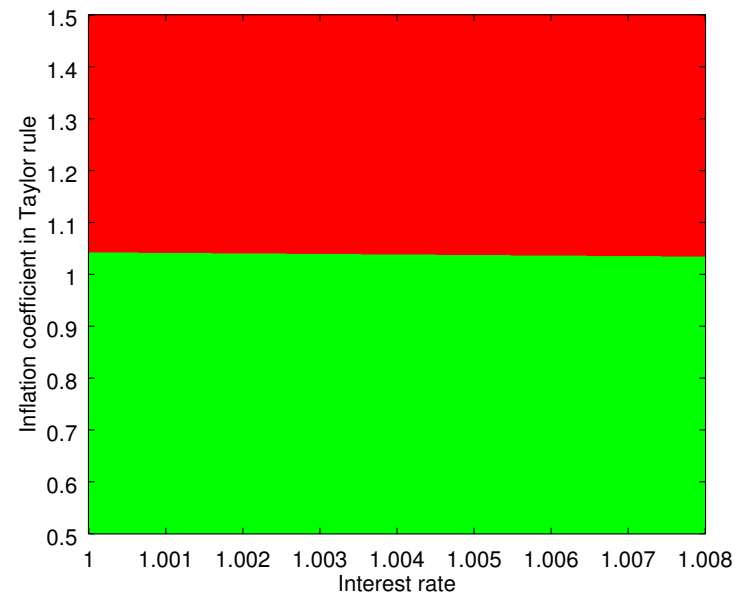

(a) Constant wage inflation, $\phi_{\nu u}=0$

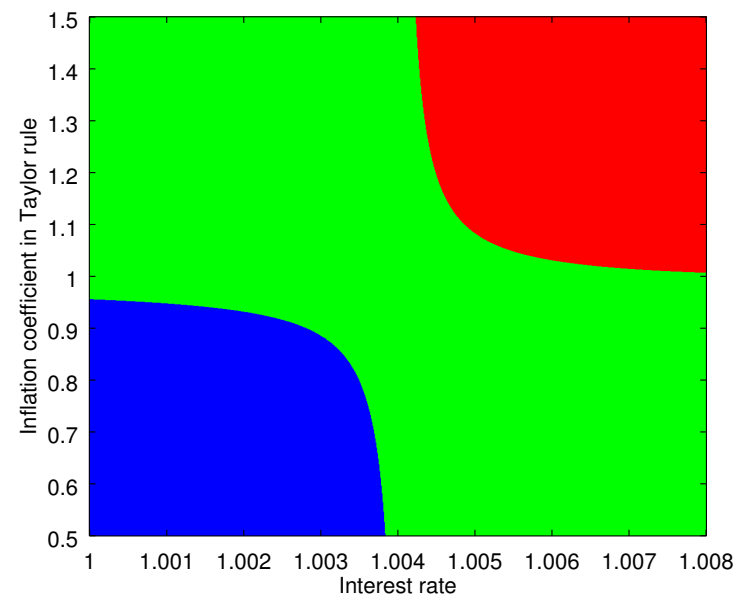

(b) Labor market feedback, $\phi_{\nu u}=2$

Figure 2: Solution properties of the DSDE model for different combinations of $\phi_{r \pi}$ and $R$ : indeterminacy (blue), determinacy (green), and non-existence (red).

rate by more than the initial rise in inflation, i.e., $\phi_{r \pi}>1$. Only in this case, the number of unstable eigenvalues will match the number of forward-looking variables and a unique and stable rational expectation solution of the DSGE model will exist. Sunspot equilibria in which an idiosyncratic shock to inflation expectations cause a self-fulfilling rise in observed inflation are ruled out. Hence, following the Taylor principle, the central bank can reduce macroeconomic fluctuations originating in shocks to expectations. ${ }^{7}$

To study the determinacy properties of rational expectations solutions in the DSDE mode, we ask what response of the interest rate to a change in inflation, $\phi_{r \pi}$, is required for the solution to be determinate at given values of the other parameters. In particular, we ask what are the determinacy properties of the solutions for different combinations of $\phi_{r \pi}$ and the interest rate $R$, given the calibration as discussed in the next section. The range of $R$ is chosen such that meaningful steady states exist. We consider two baseline model variants without price and capital adjustment costs: a constant wage inflation DSDE model and a labor-market feedback DSDE model. Figure 2 plots the determinacy regions for the two model variants. The blue, green, and red areas indicate combinations of $\phi_{r \pi}$ and $R$ for which infinitely many solutions exist (indeterminacy), a unique solution exists (determinacy), and no solution exists, respectively.

The results are remarkable. The Taylor principle does not hold in general. In the DSDE model with constant wage inflation (panel a), solution determinacy requires $\phi_{r \pi}$ to fall roughly below 1.04 for the entire range of meaningful steady-state values of $R$. Even without any response of the interest rate to a change in inflation, a unique rational expectation solution exists. This is because of the precautionary saving motive in the household's problem. Suppose a sunspot increases expected inflation. The real interest rate drops triggering a positive inter-temporal substitution effect on consumption. Yet, wealth now accumulates on a slower pace, and the value of accumulated bonds will be persistently lower. This cuts into current consumption dominating the expansionary

\footnotetext{
${ }^{7}$ Sveen and Weinke (2007) show that the Taylor principle fails to be a sufficient condition for determinacy in case of firm-specific capital as assumed in the DSGE model considered here as well as price and wage rigidities.
} 

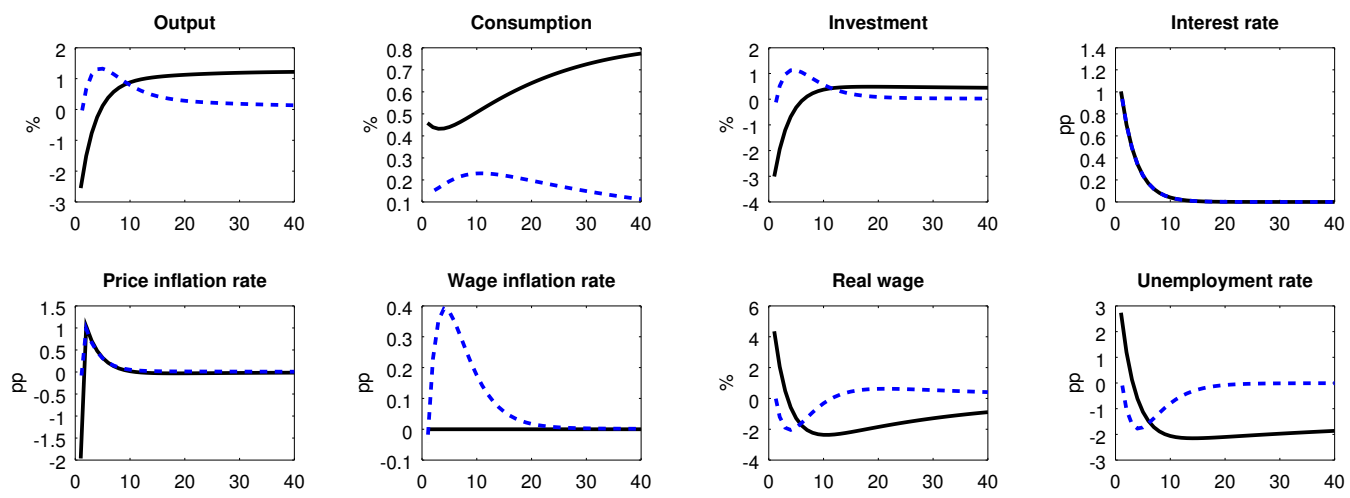

Figure 3: Macroeconomic responses of baseline specifications without a monetary policy reaction to inflation or adjustment $\operatorname{costs}\left(\phi_{r \pi}=0, \tau_{i}=0, \tau_{p}=0\right)$ to a monetary policy shock: the case of a constant rate of wage inflation $\left(\phi_{\nu u}=0\right.$, solid line) and the case of a labor market feedback to wage formation $\left(\phi_{\nu u}=2\right.$, dashed line $)$.

substitution effect. Overall, output will contract and price inflation will decrease. Hence, the macroeconomic adjustment after sunspot shocks is self-correcting and does not need monetary stabilization. In fact, a strong monetary policy response to inflation will be destabilizing. To see this, consider a monetary policy shock. The real interest rate goes up, causing output to go up due to a strong wealth effect. This triggers inflationary pressures to which the central bank responds by increasing the real interest rate further.

In the DSDE model with a labor-market feedback to wage formation (panel b), we identify two monetary policy regimes that yield unique equilibria. For large target interest rates, determinacy requires monetary policy to be rather passive for the same reasons discussed above. Yet, there exists a threshold for the target interest rate $(R=1.004)$ below of which an additional eigenvalue becomes stable. Hence, for low target interest rates, monetary policy needs to be active, similar to the Taylor principle.

\section{Impulse-response analysis}

\subsection{The role of labor market feedback for monetary policy}

To better understand the economy characterized by the DSDE model, let us discuss the propagation mechanisms of a monetary policy shock, in particular of a 1\%-point shock to the interest rate with a persistence of $\rho_{R}=0.7$. I first consider a baseline specification without a monetary policy response to inflation $\left(\phi_{r \pi}=0\right)$ or price or capital adjustment $\operatorname{costs}\left(\tau_{i}=0, \tau_{p}=0\right)$. Figure 3 plots the impulse-response functions for the case of a constant rate of wage inflation $\left(\phi_{\nu u}=0\right)$ and for the case of labor market feedback to the wage formation $\left(\phi_{\nu u}=2\right)$.

In the economy without labor market feedback, a 1\%-point increase in the interest rate with a persistence of 0.7 causes output to decline by $2.5 \%$ which is quite strong. This is mainly driven by a contraction of investment as consumption increases on impact. Unemployment goes up by $3 \%$-points. In the absence of adjustment costs, prices to drop on impact which is associated with an increase in the real wage. Thereafter, prices jump upwards causing the real interest rate to 
increase slightly.

The assumptions of precautionary saving and firm-specific capital determine the shapes of these responses. The risk of permanent income loss makes consumption dependent on wealth. Hence, even a temporary shock to the interest rate has long-lasting effects on consumption due to a shift in wealth arising from the household sector's budget constraint. The contraction of investment and the strong response of price inflation are due to firm-specific capital.

To see why the plotted IRFs are the solution paths, recall the absence of adjustment costs and consider the following thought experiments on the firm side. Suppose the firms decrease prices and expect them to stay low such that the real wage and especially the real interest rate increase. By the FOC w.r.t. labor in (11), the current price is chosen such that the marginal cost of labor equals its marginal return at the given equilibrium output. With predetermined capital, a higher real wage is associated with a lower output-capital ratio $\tilde{Y}_{t} / \tilde{K}_{t-1}$. That means equilibrium output needs to go down if firms choose to set prices such that the real wage increases. Given the strong increase in the real interest rate, the FOC w.r.t. capital in (13), firms prefer to decrease the capital stock considerably for a given level of expected output, i.e. strongly increase the expected output capital ratio $\mathrm{E}_{t} \tilde{Y}_{t+1} / \tilde{K}_{t}$. For the sake of exposition, suppose consumption is constant. Then, the decrease in $\tilde{Y}_{t} / \tilde{K}_{t-1}$ can only come from a drop in investment which decreases $K_{t}$ by the law of motion of capital in (14). Then, $\mathrm{E}_{t} \tilde{Y}_{t+1} / \tilde{K}_{t}$ will decrease but not sufficiently. It additionally requires an a drop in $\mathrm{E}_{t} \tilde{Y}_{t+1}$. This, in turn, requires an even stronger drop in investment in the next period. Hence, a strong and persistent decrease in prices is not consistent with the solution path of the rational expectations model.

Now, suppose the firms increase prices considerably and expect them to stay high such that the real wage and, to some extent, the real interest rate decrease. The exact opposite reasoning applies. By the FOC w.r.t. labor $\tilde{Y}_{t} / \tilde{K}_{t-1}$ is required to increase strongly. By the FOC w.r.t. capital $\mathrm{E}_{t} \tilde{Y}_{t+1} / \tilde{K}_{t}$ is required to slightly decrease. The required increase in output can only be achieved by a sufficiently strong increase in investment which, however, creates too much capital for next period's output-capital ratio to decrease only slightly. Expected output needs to decrease as well. Yet, this requires a further reduction in investment and capital. Again, the contemplated behavior is not consistent with the rational expectation model.

The solution requires the firms to expect positive but sufficiently low inflation. Then the real interest rate will go up but not by as much as in the first thought experiment. The expected output-capital ratio has to increase due to the FOC w.r.t. capital. Again, a reduction of investment decreases the capital stock to the desired level. This drop in investment reduces current output and, by the FOC w.r.t. labor, is associated with an increase in the real wage. Hence, rational expectations will induce firms to do the following: first, decrease prices on impact in order to increase the real wage associated with a lower output; second, increase prices thereafter to increase the real interest rate such that the required reduction of capital is consistent with the reduction in current demand.

With labor market feedback, the additional complication is that the unemployment rate has a positive effect on the rate of wage inflation. The short and long run effects of a monetary policy shock differ considerably from the constant-wage specification. The quantity adjustment on impact is much lower and the economy returns to the steady state much quicker. In the previous specification the drop in prices on impact was primarily to sufficiently increase the real wage such that the subsequent price inflation would not reduce the real wage by too much below steady state. With labor market feedback, however, there is almost no impact effect of monetary policy. This 

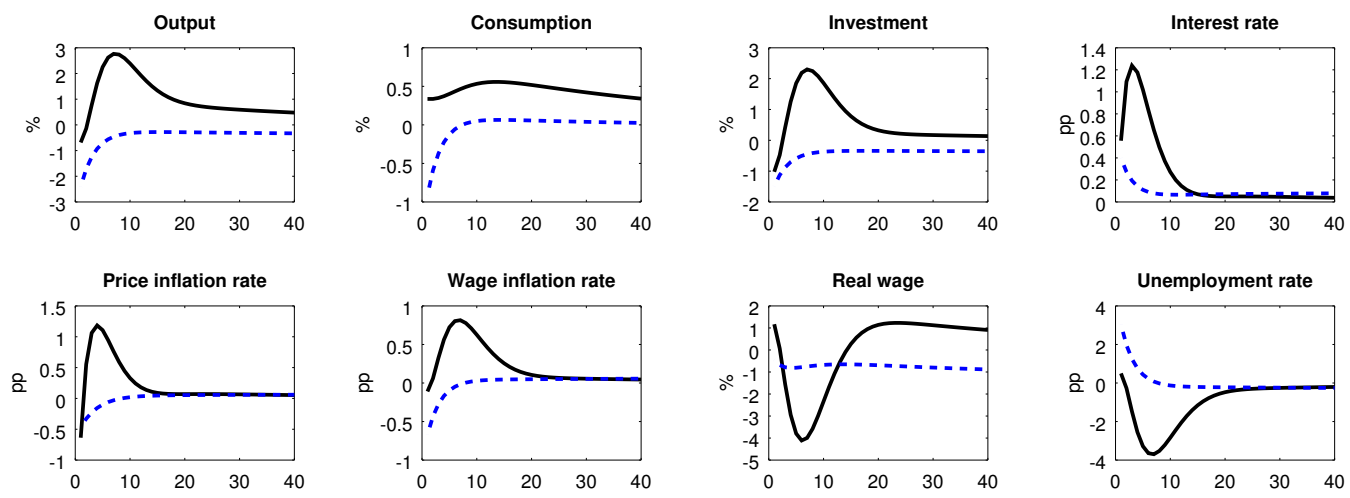

Figure 4: Macroeconomic responses of specifications with labor market feedback to wage formation and without adjustment $\operatorname{costs}\left(\phi_{\nu u}=2, \tau_{i}=0, \tau_{p}=0\right)$ to a monetary policy shock: the case of a passive monetary policy $\left(\phi_{r \pi}=0.7\right.$, solid line $)$ and the case of active monetary policy $\left(\phi_{r \pi}=1.3\right.$, dashed line).

is because the positive price inflation after impact does not increase the real wage as the nominal wage will now increase. The response of nominal wages to labor market conditions ensures that the economy returns to the neighborhood of the steady state after 15 quarters. Given that I have not assumed any adjustment costs, this persistence is quite considerable.

Note that investment and output would drop on impact if we held consumption constant. The moderate but persistent expansion of consumption which, again, is due to the level effect on wealth, counteracts the firms desire to reduce capital as a consequence of an increased real interest rate.

\subsection{Passive and active monetary policy}

In the previous impulse-response analysis, I have assumed that monetary policy does no respond to inflation. Here, I compare the macroeconomic effects of the same monetary policy shock for the cases of a passive response to inflation $\left(\phi_{r \pi}=0.7\right)$ and an active response to inflation $\left(\phi_{r \pi}=1.3\right)$. I further assume labor market feedback $\left(\phi_{\nu u}=2\right)$ and maintain the assumption of no adjustment $\operatorname{costs}\left(\tau_{i}=0, \tau_{p}=0\right)$.

Figure 4 plots the corresponding IRFs. For the case of passive monetary policy, they look similar to the specification without a monetary policy reaction to inflation considered above. There is a striking difference, however. In the current specification the responses are considerably more pronounced. This holds for both the demand components as well as price inflation itself. Hence, in the passive monetary policy regime with large steady-state interest rates, a monetary policy that responds to inflation is not only unsuccessful in taming inflation but also destabilizing.

In the active monetary policy regime, the macroeconomic responses to a monetary policy shock look familiar. Aggregate demand and its components decrease and unemployment goes up. The interest rate increases more moderately as a lower inflation induces the central bank to counteract the monetary policy shock. The rate of wage inflation decreases due to rising unemployment. Note that, due to the absence of adjustment costs, the responses to the interest rate shock are quite pronounced also in the active monetary policy regime. 

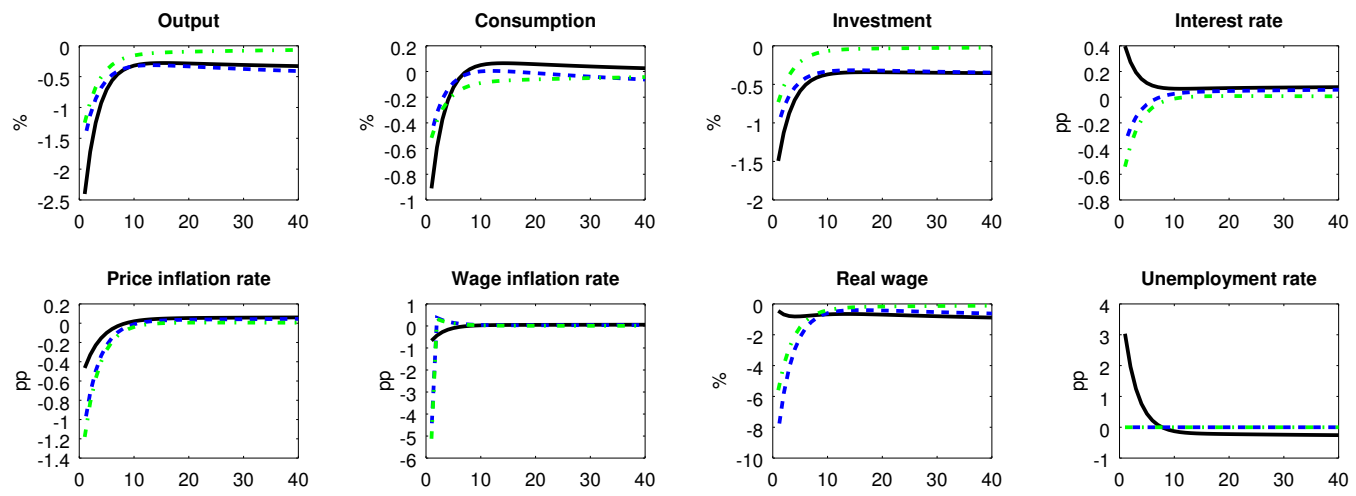

(a) Monetary policy shock
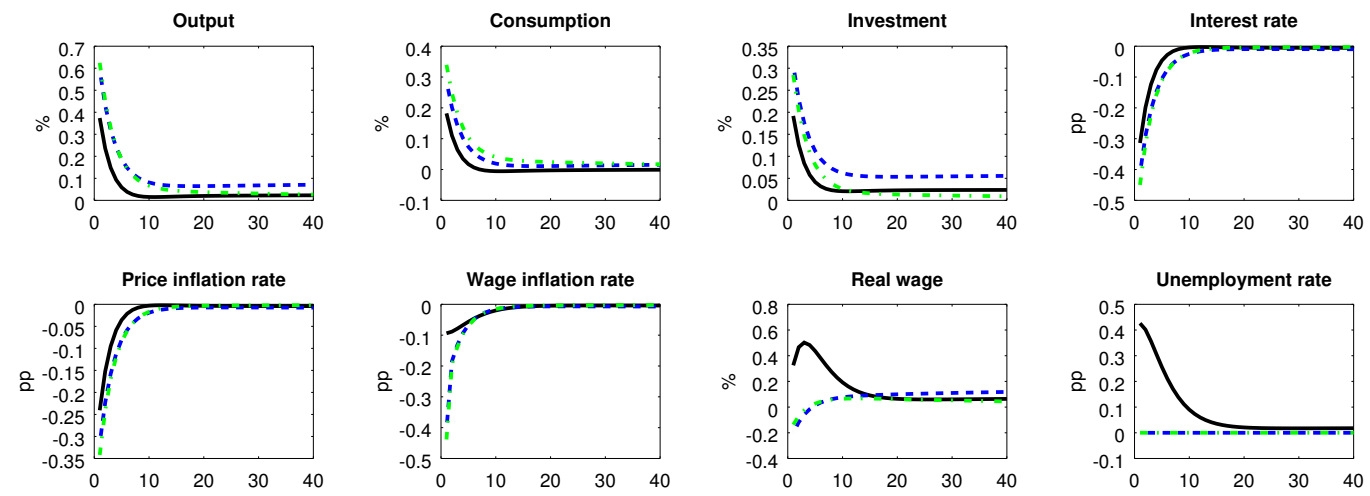

(b) Total factor productivity shock

Figure 5: Macroeconomic responses to monetary policy and total factor productivity shocks for a DSDE model with labor market feedback, adjustment costs, and active monetary policy $\left(\phi_{\nu u}=2\right.$, $\tau_{i}=20, \tau_{p}=30, \phi_{r \pi}=1.3$ ), for the corresponding precautionary saving DSGE model, and for the corresponding conventional DSGE model

\subsection{DSDE vs. DSGE}

Finally, I contrast the DSDE model with labor market feedback, capital and price adjustment costs, and active monetary policy $\left(\phi_{\nu u}=2, \tau_{i}=20, \tau_{p}=30, \phi_{r \pi}=1.3\right)$ to the corresponding precautionary saving DSGE model (DSDE model with labor market clearing nominal wage adjustment and with precautionary saving) as well as to the corresponding conventional DSGE model (DSDE model with labor market clearing nominal wage adjustment and without precautionary saving). In particular, I consider a persistent monetary policy shock and a persistent total factor productivity shock. Note that the DSGE models have been calibrated such that all three models share the same steady-state apart from the nominal interest rate.

Figure 5 plots the IRFs for the three models considered. They look quite similar across the models except for obvious differences in the unemployment rate. Further, two observations are worth to note: First, the quantitative effects of monetary policy relative to the price effects are more pronounced in the DSGE model than in the DSGE models. This is not surprising given the 
assumption of labor market clearing wage adjustment in the latter. Second, a shock to total factor productivity has positive effects in the DSDE model. Yet, they are weaker than in the DSGE models as a part of the additional productivity goes into higher unemployment. Moreover, the DSDE model predicts the real wage to increase with productivity while the DSGE models predict the opposite.

\section{Concluding remarks}

In the present paper, I have proposed a Dynamic Stochastic Disequilibrium model which combines disequilibrium theory with inter-temporal optimization and rational expectations. The core assumptions underlying the model are twofold: On the one hand, the rate of wage inflation is taken as a policy variable subject to a collective bargaining process between firms' and workers' representatives. Hence, the labor market does not have a tendency to clear and Keynesian unemployment prevails. On the other hand, I introduce an uninsurable risk of permanent income loss to the household's problem which motivates the existence of precautionary savings along the lines of Carroll (1997), Carroll and Jeanne (2009), and Carroll and Toche (2009). This gives rise to a Keynesian type of consumption function relating consumption to income and wealth.

I have identified the following core characteristics of the DSDE model and compared them to conventional DSGE models: First, output is determined from the demand side as known from the textbook IS-LM model and not from the supply side as in DSGE models. Even with fixed factor supply, a demand shock will affect output due to the presence of idle labor in equilibrium. Nevertheless, shocks on the supply side affect output through labor market feedback on the formation of wages.

Second, in contrast to DSGE models, the steady-state interest rate in the DSDE model does not have the interpretation of a natural rate. It is not determined by the household's discount rate but set by the central bank. The interest rate which implies the labor market to clear at a given rate of wage inflation which is consistent with the inflation target of the central bank may be referred to as the natural rate. Yet, there is no reason why the interest rate of the central bank should coincide with the natural rate.

Third, while dynamic efficiency in DSGE models requires the real interest rate to exceed the growth rate of the economy, there is no such thing as dynamic efficiency in the DSDE model. To ensure that the stock of wealth does no explode, the real interest rate must be below the rate of economic growth in the steady state.

Fourth, the DSDE model features two monetary policy regimes: At low steady-state interest rates, monetary policy needs to respond aggressively to inflation in order to ensure determinacy of the rational expectations solution. This is similar to the Taylor principle in the DSGE literature. Yet at high steady-state interest rates, a unique solution exists only if the central bank responds moderately to inflation.

Fifth, in the passive monetary policy regime, monetary policy responding to inflation destabilizes output and reinforces inflation.

Sixth, the macroeconomic responses to monetary policy and productivity are very similar between the DSDE model and the corresponding DSGE models. There is only three noteworthy differences: $(i)$ The adjustment of quantities relative to the adjustment of prices is more pronounced in the DSDE model than in the corresponding DSGE models; (ii) Despite its simplicity, the DSDE model allows for unemployment; (iii) productivity and the real wage move together in 
the DSDE model but not in the corresponding DSGE models. 


\section{References}

Bakshi, G. S. and Chen, Z. (1996). Inflation, Asset Prices, and the Term Structure of Interest Rates in Monetary Economies. Review of Financial Studies, 9(1):241-75.

Barro, R. J. and Grossman, H. I. (1971). A General Disequilibrium Model of Income and Employment. American Economic Review, 61(1):82-93.

Barro R, G. H. (1976). Money, Employment and Inflation. Cambridge University Press, Cambridge.

Benassy, J.-P. (1993). Nonclearing Markets: Microeconomic Concepts and Macroeconomic Applications. Journal of Economic Literature, 31(2):732-61.

Benveniste, L. M. and Scheinkman, J. A. (1979). On the differentiability of the value function in dynamic models of economics. Econometrica, 47(3):727-732.

Blanchard, O. and Gali, J. (2010). Labor Markets and Monetary Policy: A New Keynesian Model with Unemployment. American Economic Journal: Macroeconomics, 2(2):1-30.

Blanchard, O. J. (1985). Debt, deficits, and finite horizons. The Journal of Political Economy, 93(2):pp. 223-247.

Blanchard, O. J. (2016). Do dsge models have a future? Technical report, Peterson Institute for International Economics.

Caballero, R. J. and Farhi, E. (2014). The Safety Trap. NBER Working Papers 19927, National Bureau of Economic Research, Inc.

Carroll, C. D. (1997). Buffer-Stock Saving and the Life Cycle/Permanent Income Hypothesis. The Quarterly Journal of Economics, 112(1):1-55.

Carroll, C. D. and Jeanne, O. (2009). A Tractable Model of Precautionary Reserves, Net Foreign Assets, or Sovereign Wealth Funds. NBER Working Papers 15228, National Bureau of Economic Research, Inc.

Carroll, C. D. and Toche, P. (2009). A Tractable Model of Buffer Stock Saving. NBER Working Papers 15265, National Bureau of Economic Research, Inc.

Farmer, R. E. A. (2008). Aggregate demand and supply. International Journal of Economic Theory, $4(1): 77-93$.

fu Zou, H. (1995). The spirit of capitalism and savings behavior. Journal of Economic Behavior \& Organization, 28(1):131-143.

fu Zou, H. (1998). The spirit of capitalism, social status, money, and accumulation. Journal of Economics, 68(3):219-233.

Gertler, M., Sala, L., and Trigari, A. (2008). An Estimated Monetary DSGE Model with Unemployment and Staggered Nominal Wage Bargaining. Journal of Money, Credit and Banking, 40(8):1713-1764. 
Gertler, M. and Trigari, A. (2009). Unemployment Fluctuations with Staggered Nash Wage Bargaining. Journal of Political Economy, 117(1):38-86.

Hall, R. E. (2005). Employment Fluctuations with Equilibrium Wage Stickiness. American Economic Review, 95(1):50-65.

Karamessini, M. (2015). The greek social model: Towards a deregulated labour market and residual social protection. In Vaughan-Whitehead, D., editor, The European Social Model in Crisis. Is Europe Losing Its Soul? Edward Elgar.

Keynes, J. M. (1936). The General Theory of Employment, Interest and Money. Macmillan, London.

Korinek, A. and Simsek, A. (2014). Liquidity Trap and Excessive Leverage. NBER Working Papers 19970, National Bureau of Economic Research, Inc.

Malinvaud, E. (1977). The Theory of Unemployment Reconsidered. Basil Blackwell, Oxford.

Mankiw, N. G. and weinzierl, M. (2011). An Exploration of Optimal Stabilization Policy. Brookings Papers on Economic Activity, $42(1$ (Spring):209-272.

Mian, A. and Sufi, A. (2014). What explains the 2007-2009 drop in employment? Econometrica, 82(6):2197-2223.

Michaillat, P. (2012). Do Matching Frictions Explain Unemployment? Not in Bad Times. American Economic Review, 102(4):1721-50.

Michaillat, P. and Saez, E. (2014). An Economical Business-Cycle Model. NBER Working Papers 19777, National Bureau of Economic Research, Inc.

Moreira, A., Dominguez, A. A., Antunes, C., Karamessini, M., Raitano, M., and Glatzer, M. (2015). Austerity-driven labour market reforms in southern europe: Eroding the security of labour market insiders. European Journal of Social Security, 17(3):202-225.

Mortensen, D. T. and Pissarides, C. A. (1994). Job Creation and Job Destruction in the Theory of Unemployment. Review of Economic Studies, 61(3):397-415.

Romer, P. (2016). The trouble with macroeconomics.

Shimer, R. (2005). The Cyclical Behavior of Equilibrium Unemployment and Vacancies. American Economic Review, 95(1):25-49.

Smets, F. and Wouters, R. (2003). An estimated dynamic stochastic general equilibrium model of the euro area. Journal of the European Economic Association, 1(5):1123-1175.

Sveen, T. and Weinke, L. (2007). Firm-specific capital, nominal rigidities, and the Taylor principle. Journal of Economic Theory, 136(1):729-737. 


\section{A Calibration}

This section reports the calibration of the benchmark DSDE model simulated in Figure 5. Whenever calibration deviates from this, it is made explicit in the main text.

\begin{tabular}{|c|c|c|}
\hline \multicolumn{3}{|c|}{ Parameters } \\
\hline \multicolumn{3}{|c|}{ Unrestricted calibration } \\
\hline$\Gamma$ & Growth factor of labor-embodied productivity & 1.01 \\
\hline$\beta$ & Household's discount rate & 0.998 \\
\hline$D$ & Inactive household's probability of death & 0.002 \\
\hline$\eta$ & Inverse of the Frisch labor supply elasticity & 1 \\
\hline$\delta$ & Rate of capital depreciation & 0.025 \\
\hline$\epsilon$ & Elasticity of substitution of intermediate goods & 3 \\
\hline$\lambda$ & Target debt-capital ratio & 0.15 \\
\hline$\tau_{i}$ & Investment adjustment cost scaling parameter & 20 \\
\hline$\tau_{p}$ & Price adjustment cost scaling parameter & 30 \\
\hline$\phi_{r \pi}$ & Inflation elasticity of interest rate & 1.3 \\
\hline$\phi_{\nu u}$ & Unemployment elasticity of the workers' bargaining power & 2 \\
\hline$\rho_{R}$ & Persistence of a monetary policy shock & 0.7 \\
\hline$\rho_{A}$ & Persistence of a productivity shock & 0.7 \\
\hline$\tilde{G}$ & Steady-state government expenditures & 0.2 \\
\hline$\Pi$ & Target inflation rate of monetary authority & 1 \\
\hline$R$ & Interest rate target of the monetary authority & 1.004 \\
\hline$A$ & Steady-state total factor productivity & 1 \\
\hline \multicolumn{3}{|c|}{ Restricted recursive calibration } \\
\hline$U$ & $\begin{array}{l}\text { Active household's probability of income loss } \\
\text { (such that old-age dependency ratio } U / D \text { is } 0.3 \text { ) }\end{array}$ & 0.0006 \\
\hline$\kappa$ & $\begin{array}{l}\text { Steady-state consumption-wealth ratio of inactive household } \\
\text { (follows from } 1-\beta(1-D) \text { ) }\end{array}$ & 0.004 \\
\hline$\theta$ & $\begin{array}{l}\text { Scaling parameter of consumption utility } \\
\text { (such that } Y=1 \text { at the steady state) }\end{array}$ & 0.9614 \\
\hline$\alpha$ & $\begin{array}{l}\text { Output elasticity of capital } \\
\text { (such that } Y / K=0.1 \text { at the steady state) }\end{array}$ & 0.435 \\
\hline$\psi$ & $\begin{array}{l}\text { Scaling parameter of labor disutility } \\
\text { (such that } u=0 \text { at the steady state) }\end{array}$ & $7 \mathrm{e}+07$ \\
\hline$\nu$ & $\begin{array}{l}\text { Steady-state workers' bargaining power } \\
\left.\text { (such that } \Pi_{w}=\Pi\right)\end{array}$ & 0.713 \\
\hline
\end{tabular}

